\title{
Parasitoid wasps indicate that the marsh fritillary butterfly (Euphydryas aurinia) has persisted on Tiree rather than re-colonised recently
}

\author{
N.O.M. Ravenscroft \\ Oakfield, Achindarroch, Appin, Argyll PA38 4BS \\ E-mail: neil@wildsideecology.com
}

\begin{abstract}
The population of the marsh fritillary butterfly (Euphydryas aurinia) in western Scotland fluctuates greatly and the species is difficult to locate during periods of scarcity. It was recorded on Tiree in 2014 for the first time in 64 years during a period of abundance. The nearest known populations occur $40 \mathrm{~km}$ to the east and its discovery represents either a recent colonisation event well beyond its known capability or it has escaped detection for a longer period. Surveys for the larval cocoons of two wasps that are parasitoids of E. aurinia and host-specific were undertaken on Tiree in spring and autumn 2017. The adult wasps are small with limited powers of dispersal and are unlikely to have followed E. aurinia to Tiree since 2014. Cocoons of one species - Cotesia melitaearum - were abundant in all concentrations of E. aurinia in spring 2017 but neither species was found in the autumn. The absence of the second species C. bignellii - is inconclusive as it was also absent at known locations elsewhere in autumn 2017. The occurrence, distribution and abundance of C. melitaearum on Tiree indicate that E. aurinia had been present for some time before its discovery in 2014. Although continuous presence since 1950 cannot be extrapolated with certainty, the results highlight the propensity of E. aurinia to persist for long periods in numbers that fall below the observation threshold, even in areas of high wildlife awareness, and that it is not always an easy species to record.
\end{abstract}

\section{INTRODUCTION}

The marsh fritillary (Euphydryas aurinia) is a species of high conservation concern and is protected in the European Union as it is still declining in large parts of the U.K. and Europe. In common with similar species, it is relatively immobile, and fragmentation of its habitat and the isolation of populations are the principal factors in its decline, limiting the recolonisation of habitat after local extinction (Ehrlich \& Hanski, 2004; Schtickzelle et al., 2005).

The species fluctuates greatly in abundance from year to year throughout its range, even at sites with apparently ideal habitat that are under recommended management. Although its biology is not understood fully despite its status, two parasitoids that are specific to E. aurinia are known to cause high caterpillar mortality in some years.

The western seaboard of Scotland supports one of the principal concentrations of E. aurinia in the U.K. Here it is common in coastal Argyll and on the larger Inner Hebrides such as Mull, Islay, Jura and Lismore. Even so, understanding of its status in the region is incomplete. For example, it has been recorded in over 200 new $1 \mathrm{~km}$ squares in the last 20 years on Islay. Populations in Scotland utilise more varied habitats than elsewhere in the U.K. and occupy marginal agricultural land that is grazed or abandoned.

The butterfly was recorded on Tiree in 2014 during a period when it was abundant elsewhere in western Scotland. This was the first record on the island since 1950 (NBN Atlas, 2016) and subsequent observations revealed both adults and caterpillars to be widespread (J. Bowler, pers. comm.). Tiree is $30 \mathrm{~km}$ west of the nearest land (Mull) that is known to support E. aurinia, and $40 \mathrm{~km}$ from the nearest known populations on the Ross of Mull and Mishnish. Tiree is a relatively small island $\left(\mathrm{ca} .80 \mathrm{~km}^{2}\right)$ and its fauna and flora, especially its birds, have been recorded intensively (e.g. Bowler \& Hunter, 2007; Bowler et al., 2008). The appearance of E. aurinia presents a puzzle, therefore, as it represents either a recent long-range colonisation event far beyond its known capability or long-term persistence that has escaped observation in an area of high wildlife awareness.

This study in 2017 aimed to establish if the hostspecific parasitoids of E. aurinia are present on Tiree. These are small braconid wasps with a wingspan of 2-3 $\mathrm{mm}$ and typically with more limited powers of dispersal than their hosts (Lei \& Hanski, 1998; van Nouhuys \& Hanski, 2002) and are unlikely to have tracked the butterfly to Tiree since 2014 . Their absence would suggest that colonisation by E. aurinia is recent and their presence would confirm longer-term presence of the butterfly.

\section{THE STUDY SPECIES}

The marsh fritillary flies mainly in June in Scotland, and its eggs hatch in July. Caterpillars live gregariously and cryptically during the early stages of growth but construct prominent "webs" of silk on the foodplant 
devil's-bit scabious (Succisa pratensis) towards the end of August, when they are 2nd instars (caterpillars moult between each instar, or stage of growth). Feeding webs of the 3rd instar are visible through to the moult to the 4th instar in September or early October when the caterpillars construct a web deep in the vegetation and hibernate. Caterpillars emerge from hibernation most usually in early-mid March and develop quite slowly to reach the 5th instar in late March or early April. These grow rapidly to reach the final 6th instar in mid-April and pupation by early May (pers. obs.).

Two conspecific parasitoids - Cotesia melitaearum and C. bignellii - attack E. aurinia and are specific to it in Scotland. "C. melitaearum" is an aggregate of morphologically identical cryptic species each of which may be specific to one host within the tribe of butterflies (Melitaeini) which includes E. aurinia (Kankare \& Shaw, 2004; Kankare et al., 2005). Cotesia melitaearum is widespread but $C$. bignellii was recorded for the first time in 2014, on Islay (pers. obs.). Elsewhere both species have up to three generations per generation of E. aurinia (Porter, 1979; Stefanescu et al., 2009). Three generations of $C$. bignellii do occur on Islay, but only two of $C$. melitaearum have been recorded so far: a third generation of the latter has yet to be recorded in Scotland (M.R. Shaw, pers. comm.).

The spring generation of both species is evident when one or two wasp larvae emerge from caterpillars of E. aurinia, usually when 4th instars moult in late March and early April, and spin cocoons in which to pupate. The cocoons of C. melitaearum are relatively easy to spot in or around the feeding and moult webs of 4th instar caterpillars (Fig. 1), but those of C. bignellii are difficult to locate as caterpillars harbouring this species may disperse and hide before wasp larvae emerge (pers. obs.).
The adult wasps that emerge from these cocoons attack 5th and 6th instar caterpillars of E. aurinia in April before they reach pupation. Affected caterpillars harbour many wasp larvae and these erupt in the summer, producing a mass of cocoons. This summer generation of wasps attacks early instar caterpillars of the next generation of E. aurinia and wasp larvae enter hibernation with E. aurinia, emerging in the spring to complete the cycle. Some of these wasp larvae develop early, emerge and spin cocoons before the hibernation of E. aurinia, producing a third, autumn generation of wasps. These attack caterpillars of E. aurinia just before or while they are in hibernation (pers. obs.).

\section{METHODS}

\section{General}

Two visits were made to Tiree in 2017, in spring (9th - 11th April) and autumn (8th - 10th October). These were timed to coincide with respectively the spring moult of 4th instars when wasp cocoons, especially those of $C$. melitaearum, are most visible, and the autumn moult of 3rd instars and hibernation of 4th instars when cocoons of $C$. bignellii (and sometimes adults) can be found in late feeding webs and final moult webs. This information was obtained outwith Tiree through monitoring the development of caterpillars on Islay and mainland Argyll.

Both visits were timed well, although the development of caterpillars on Tiree lagged slightly compared with elsewhere in 2017. Searches were made for webs in suitable habitat when it was encountered on the ground within $200 \mathrm{~m}$ x $200 \mathrm{~m}$ units of $1 \mathrm{~km}$ squares (therefore a $1 \mathrm{~km}$ square was composed of 25 such units).

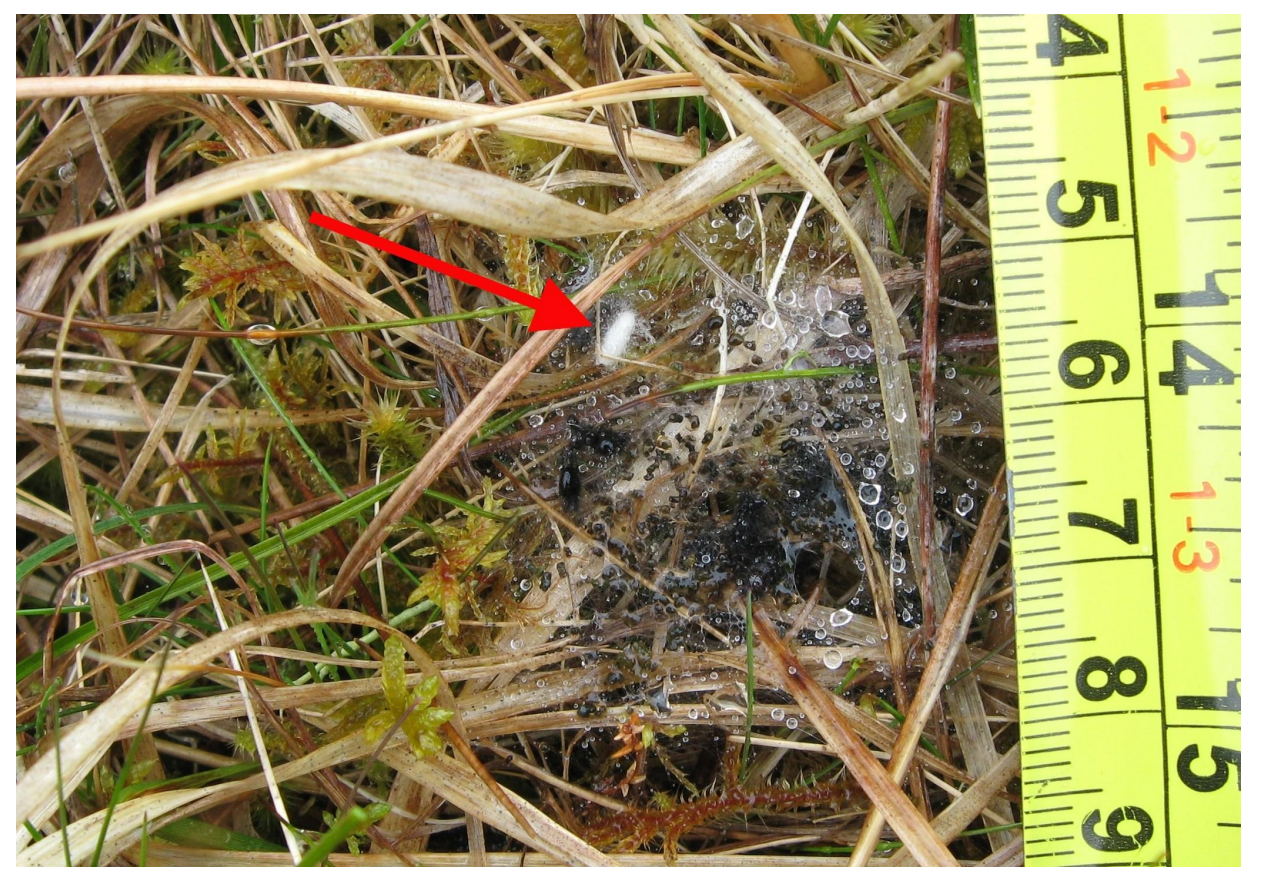

Fig. 1. A cocoon of the parasitoid wasp Cotesia melitaearum (arrowed) inside an empty spring moult web of the marsh fritillary (Euphydras aurinia) on Tiree, Scotland, April 2017. 


\section{Spring}

Surveys for webs in the spring focused on four lochs on the "sliabh" of Tiree, an expanse of wet, peaty ground in the centre of the island on which E. aurinia had been seen in 2014-2016 (Fig. 2). These were Loch na Gile (NM027481), Loch Riaghain (NM034471), Loch a' Bhleoghainn (NM021456) and Loch Leana na Moine (NM028446), as well as areas beside the B8069. The location (10 figure grid reference) of all webs found was recorded using a GPS and the number of cocoons in each web was counted. Webs were broken and searched if caterpillars had vacated them. All cocoons were collected.

\section{Autumn}

Surveys were repeated within the spring search area but also expanded to encompass adjacent and new areas, especially around Loch Caol (NM030454) (Fig. 2), primarily because of the paucity of webs of $E$. aurinia. The locations of all webs that were located were recorded and all empty webs were broken and searched for cocoons. To provide a baseline for future monitoring, transects were walked during which the numbers of E. aurinia webs were recorded in standard fashion (counted $1 \mathrm{~m}$ either side of the observer and route length recorded).

\section{RESULTS}

Spring

Eighty nine webs of E. aurinia were located in 11 of 35 survey units during spring 2017 (Fig. 3A). Concentrations of webs were found in three survey units, one each beside Loch Riaghain, Loch a' Bhleoghainn and Loch Leana na Moine (these three units contained 67 webs or $75 \%$ of the total).

Remaining webs were spread thinly and almost half of occupied search units contained two or fewer webs.

Most caterpillars of E. aurinia were 4th instars in webs and were either approaching moult or were at moult. Small 5th instars occurred in and around these webs indicating freshly moulted caterpillars. Some larger 5th instars and several 6th instars occurred in some survey units, and these occupied a further seven units in the absence of any evidence of 4 th instars.

Cocoons were found in 47 webs (i.e. $53 \%$ or about one in two webs contained cocoons). Ninety nine cocoons were found in total, i.e. about two per parasitised web overall, but up to seven occasionally (Fig. 4). Numbers of webs and cocoons in units were correlated highly (Spearman's $r=0.91, P=0.001$ ); $85 \%$ of cocoons occurred in three survey units that contained $75 \%$ of the population of E. aurinia. Cocoons were not found in four of the five units that contained only one or two webs of E. aurinia (Fig. 3B).
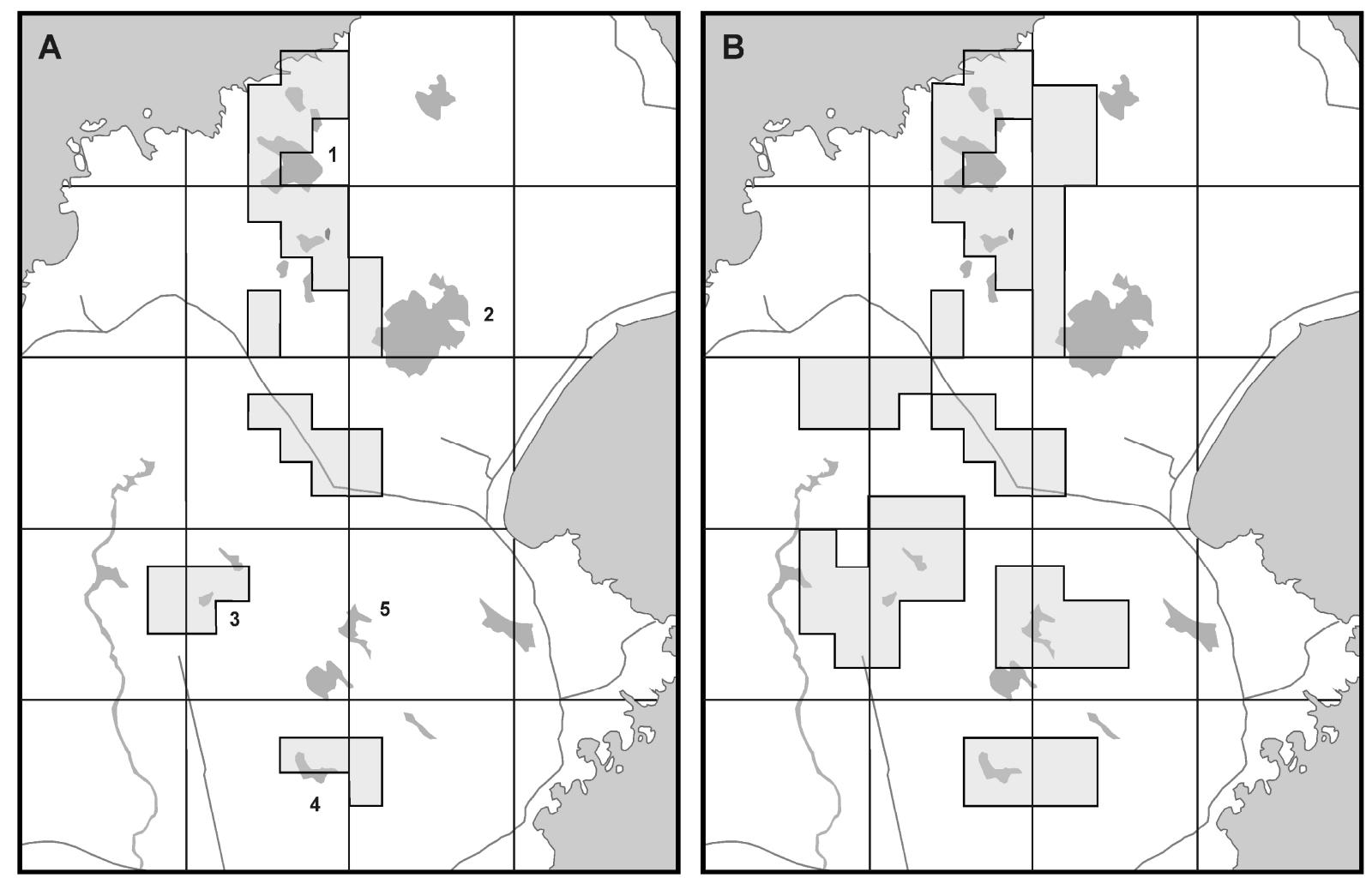

Fig. 2. Maps of the sliabh of Tiree, Scotland, on which searches for E. aurinia caterpillars were performed within the shaded areas during (A) spring 2017 and (B) autumn 2017. Search areas are shown against a background of water bodies (dark grey), roads and the $1 \mathrm{~km}$ grid. 1, Loch na Gile; 2, Loch Riaghain; 3, Loch a' Bhleoghainn; 4, Loch Leana na Moine; 5, Loch Caol. 

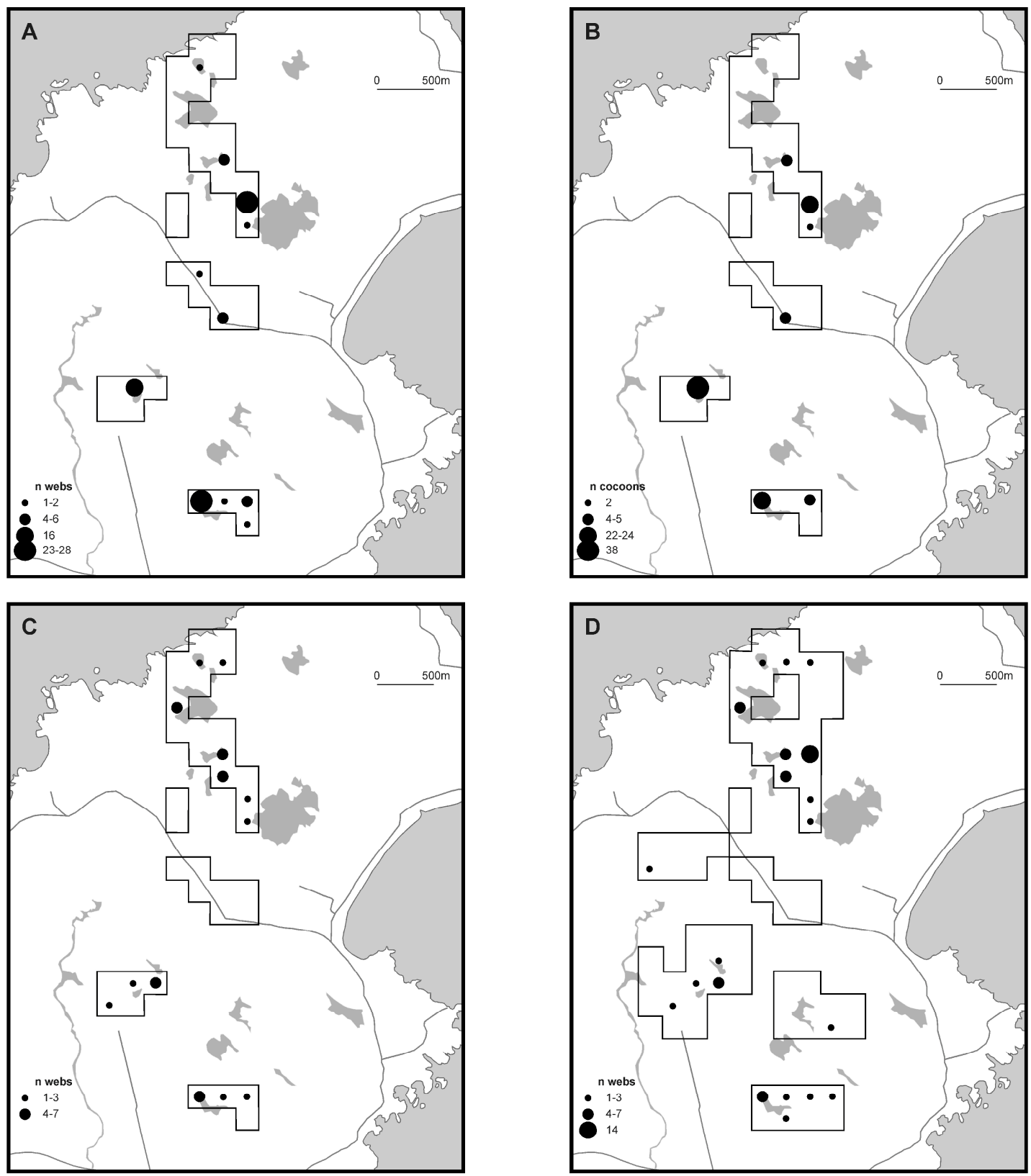

Fig. 3. Maps of the sliabh of Tiree, Scotland, showing the distributions and numbers in 2017 of (A) webs of 4th instar caterpillars of E. aurinia in spring, (B) cocoons of C. melitaearum in spring, (C) webs of E. aurinia in autumn within the same search area, and (D) webs of E. aurinia in autumn within the wider search area.

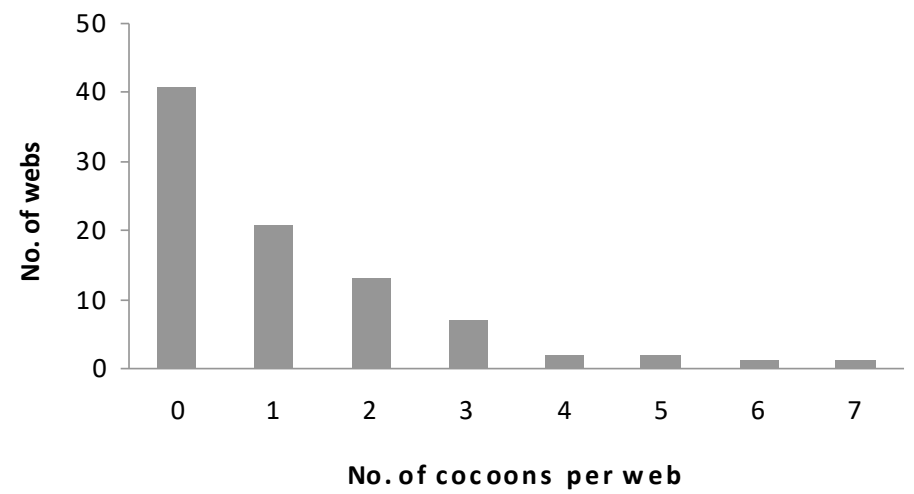

Fig. 4. The frequency of cocoons of C. melitaearum in webs of E. aurinia on Tiree, Scotland, in spring 2017. 
All wasps that hatched from collected cocoons were C. melitaearum: 36 males and 57 females (six cocoons did not hatch). Sex ratios were biased towards females at Loch a' Bhleoghainn (males:females 7:28), but equal elsewhere (29:29). Parasitism rates were high at Loch a' Bhleoghainn where $75 \%$ of webs contained at least one cocoon and 38 cocoons occurred in 12 parasitised webs.

\section{Autumn}

Webs occurred at a lower density than in the spring (Fig. 3C). Thirty nine webs were located in 13 survey units, usually in small numbers (only one to three webs were found in eight of these squares). Spring and autumn distributions were not correlated $(r=-0.12)$. The web total increased to 64 in 20 of 77 survey units in the expanded survey area, again occurring most usually as scattered webs (one to three webs were found in 14 of these units; Fig. 3D). Only one concentration of webs was recorded.

Most caterpillars had entered hibernation: 51 webs were empty final moult webs and the other 13 webs contained 4th instars. All the former were broken and searched but no wasp cocoons were found and none was observed in occupied webs.

\section{DISCUSSION}

\section{Colonisation or persistence?}

The occurrence of $C$. melitaearum on Tiree indicates strongly that $E$. aurinia was present before its discovery in 2014. The wasp is unlikely to have reached Tiree naturally since then, or colonised the extent of the island in which it was recorded in 2017. For example, each generation of the $C$. melitaearum agg. that attacks the Glanville fritillary Melitaea cinxia in Finland has a typical range of less than $500 \mathrm{~m}$ (Lei \& Camara, 1999; van Nouhuys \& Hanski, 2002). Owing to its restricted mobility, the wasp exists only in well-connected and enduring populations of $M$. cinxia and becomes concentrated in areas of high host density (Lei \& Hanski, 1998; van Nouhuys \& Hanski, 2002). This is exactly what was found on Tiree, where C. melitaearum occurred almost exclusively in concentrations of $E$. aurinia and the numbers of cocoons and webs were correlated. This gives every indication that both $C$. melitaearum and E. aurinia are well established on the island.

The failure to locate $C$. bignellii is inconclusive, as it is more cryptic than $C$. melitaearum, and its range in Scotland outside Islay is unknown. Furthermore, although $C$. bignellii had an autumn generation on Islay for three years after its discovery, none were found on the island in the autumns of 2017 or 2018. The synchrony between wasps and E. aurinia larvae early in the summer probably affects the occurrence of the autumn generation and it is believed to be partial (Porter, 1983). Therefore, the lack of cocoons does not indicate that $C$. bignellii is absent. It is interesting that the flightless ichneumonid Gelis sp., a generalist hyperparasitoid of the wasps that is common in cocoons of both species on Islay, was not found on Tiree.
How long E. aurinia has been on Tiree is impossible to predict but it is conceivable that it has persisted since 1950. Populations drop to extremely low levels in Scotland and caterpillars can be extremely difficult to find. At these times they can escape casual observation, as has been noted in England (Porter, 1990). For example, marsh fritillaries declined to such low levels at one well-studied site in Cumbria from a period of abundance in the late 19th century, when larvae occurred in "swarms", that it was only observed occasionally during thorough searches for nearly 20 years, until a second period of super-abundance (Ford $\&$ Ford, 1930). On Islay, numbers may drop so low that an impression of absence or local extinction can be gained by standard survey techniques, but protracted searches often reveal its presence, usually only when repeated. The species is difficult to record at these times, and a recorded absence over larger areas that it is known to occupy, even after searches by experienced observers, could be no more than an indication of very low density.

Heslop Harrison (1943, 1946) recorded the marsh fritillary on Tiree and more widely in the Inner Hebrides, including Coll, Gunna and Rum but, as with many of his records, it has not been seen since on these islands. Although the veracity of some of his records has been questioned, there is no reason to doubt those of E. aurinia and it seems probable that Heslop Harrison was active during a spell of abundance for it to be recorded so readily. Recently, the butterfly has been found on Eigg after an absence of nearly 30 years where it was found to be widespread; and it has been re-located on Gunna since the discovery on Tiree (J. Bowler, pers. comm.). It has also been recorded on Bute after a protracted absence, and subsequently found to occur more widely (NBN Atlas, 2016).

Numerous biological surveys have been performed on Tiree since Heslop Harrison's time, some of which covered the areas in which E. aurinia occurs currently (e.g. Shepherd \& Stroud, 1991). In the early days, sightings of E. aurinia may not have been noteworthy as it was known to occur on the island. Latterly though, wildlife awareness is high amongst both resident and visiting naturalists. Bird surveys continue to cover the sliabh but these tend to be early morning and at a time of year when E. aurinia is either a caterpillar, pupa or in hibernation. Adult butterflies are imperceptible in any case during periods of poor weather, especially during low ebbs in the population. In recent times E. aurinia has been abundant in western Scotland only in 1978, 1985, 1990-91, 1997-98, 2006-07 (when it was found on Bute) and 2013-14 (when it appeared on Eigg and Tiree) (Ravenscroft, 2013).

It seems probable that E. aurinia has been on Tiree since 1950 or, even if absent occasionally, it may have persisted on nearby Gunna or Coll, which are $c a .1 \mathrm{~km}$ distant. The butterfly is a poor disperser with distances moved generally small ( $<500 \mathrm{~m}$ : Schtickzelle et al., 2005), and although butterflies are thought to disperse a few kilometres on occasions (Porter, 1990), this is 
over land. Crossing $30 \mathrm{~km}$ of sea against the prevailing wind is a different matter. During many years of observation in an island landscape in Finland, the longest distance achieved by $M$. cinxia, a species related closely to E. aurinia and of similar size and population structure, was $6.5 \mathrm{~km}$ (van Nouhuys \& Hanski, 2002).

Human beings may have facilitated the original colonisation of Tiree by E. aurinia and C. melitaearum, perhaps through the transport of hay, livestock or fuel. Eggs of E. aurinia, wasp cocoons or young caterpillars infected with wasp eggs or larvae, might have persisted in local, fresh summer-cut hay that was imported or carried with the transport of livestock. Peat used to be cut on Mull and brought to the island after the supply on Tiree was exhausted (Banks, 1977), but this practice stopped in the 1950s with the advent of coal brought by puffers (J. Bowler, pers. comm.). Hay is still imported, but from distant sources and only as silage.

\section{ACKNOWLEDGEMENTS}

This study was made possible by a grant from the Glasgow Natural History Society through the Blodwen Lloyd Binns Bequest Fund for which I am grateful. I thank Mark Shaw and John Bowler, Tiree Officer for RSPB Scotland, for discussion and support.

\section{REFERENCES}

Banks, N. (1977). Six Inner Hebrides. David \& Charles, Newton Abbot.

Bowler J. \& Hunter J. (2007). Birds of Tiree and Coll. Tiree \& Coll Bird Book.

Bowler J., Grant, E., Self, C. \& Wellock, S. (2008). Wild Flowers of Coll and Tiree. Cinquefoil Publishing.

Ehrlich, P.R. \& Hanski, I. (2004). On the Wings of Checkerspots. Oxford University Press, Oxford.

Ford, H.D. \& Ford, E.B. (1930). Fluctuation in numbers and its influence on variation, in Melitaea aurinia, Rott. (Lepidoptera). Transactions of the Entomological Society of London 78, 345-351. https://doi.org/10.1111/j.1365-2311.1930.tb00392.x

Heslop Harrison, J.W. (1943). The range of the Greasy Fritillary Euphydryas aurinia in the Hebrides and some possible deductions therefrom. The Entomologist's Journal and Record of Variation 55, 27.

Heslop Harrison, J.W. (1946). The Lepidoptera of the Hebridean Isles of Coll, Tiree and Gunna, with some remarks on the biogeography of the islands. The Entomologist's Journal and Record of Variation 58, 57-61.

Kankare, M. \& Shaw, M.R. (2004). Molecular phylogeny of Cotesia Cameron, 1891 (Insecta: Hymenoptera: Braconidae: Microgastrinae) parasitoids associated with Melitaeini butterflies (Insecta: Lepidoptera: Nymphalidae: Melitaeini). Molecular Phylogenetics and Evolution 32, 207220. https://doi.org/10.1016/j.ympev.2003.11.013

Kankare, M., Stefanescu, C., van Nouhuys, S. \& Shaw, M.R. (2005). Host specialization by Cotesia wasps
(Hymenoptera: Braconidae) parasitizing speciesrich Melitaeini (Lepidoptera: Nymphalidae) communities in north-eastern Spain. Biological Journal of the Linnean Society 86, 45-65. https://doi.org/10.1111/j.1095-8312.2005.00523.x

Lei, G.C. \& Camara, M.D. (1999). Behaviour of a specialist parasitoid, Cotesia melitaearum: from individual behaviour to metapopulation process. Ecological Entomology 24, 59-72. https://doi.org/10.1046/j.1365-2311.1999.00167.x

Lei, G.C. \& Hanski, I. (1998). Spatial dynamics of two competing specialist parasitoids in a host metapopulation. Journal of Animal Ecology 67, 422-433. https://doi.org/10.1046/j.1365-2656.1998.00204.x

National Biodiversity Network (NBN) Atlas (2016). https://www.nbnatlas.org . Accessed 12th August 2016.

Porter, K. (1979). A third generation of Apanteles bignellii Marsh (Hym., Braconidae). Entomologist's Monthly Magazine 114, 214.

Porter, K. (1983). Multivoltinism in Apanteles bignellii and the influence of weather on synchronisation with its host Euphydryas aurinia. Entomologia Experimentalis et Applicata 34, 155-162. https://doi.org/10.1111/j.1570-7458.1983.tb03311.x

Porter, K. (1990). Eurodryas aurinia (Rottemburg) The Marsh Fritillary. In: Maitland Emmet, A. \& Heath, J. (Editors). The Butterflies of Great Britain and Ireland. Vol. 7(1), pp. 234-237. Harley, Colchester.

Ravenscroft, N.O.M. (2013). The distribution and habitat of the marsh fritillary Euphydryas aurinia during a phase of population contraction on Islay, Scotland. Scottish Natural Heritage Commissioned Report No. 593.

Schtickzelle, N., Choutt, J., Goffart, P., Fichefet, V. \& Baguette, M. (2005). Metapopulation dynamics and conservation of the marsh fritillary butterfly: Population viability analysis and management options for a critically endangered species in Western Europe. Biological Conservation 126, 569581. https://doi.org/10.1016/j.biocon.2005.06.030

Shepherd, K.B. \& Stroud, D. (1991). Breeding waders and their conservation on the wetlands of Tiree and Coll, Inner Hebrides. Wildfowl 42, 108-117.

Stefanescu, C., Planas, J. \& Shaw, M.R. (2009). The parasitoid complex attacking coexisting Spanish populations of Euphydryas aurinia and Euphydryas desfontainii (Lepidoptera: Nymphalidae, Melitaeini). Journal of Natural History 43, 553568. https://doi.org/10.1080/00222930802610444

Van Nouhuys, S. \& Hanski, I. (2002). Colonization rates and distances of a host butterfly and two specific parasitoids in a fragmented landscape. Journal of Animal Ecology 71, 639-650. https://doi.org/10.1046/j.1365-2656.2002.00627.x 